\title{
ENSINO DE GEOGRAFIA: REPRESENTAÇÕES SOCIAIS E SABERES DOCENTES NA DIRETORIA DE ENSINO DE LIMEIRA (SP)
}

\author{
Teaching of Geography: social representations knowledge in the Diretoria de Ensino de \\ Limeira (SP) \\ Iára Leme Russo Cury* \\ José Gilberto de Souza ** \\ ${ }^{*}$ Professora EBTT - IFSP / Bragança Paulista - iara.cury@ifsp.edu.br \\ ** Professor do PPG em Geografia - UNESP- Rio Claro -jgilbert@rc.unesp.br
}

Recebido em 10/08/2018. Aceito para publicação em 20/08/2018.

Versão online publicada em 03/09/2018 (http://seer.ufrgs.br/paraonde)

\begin{abstract}
Resumo:
O trabalho apresenta uma reflexão sobre os conteúdos no currículo de Geografia desenvolvido pelos Professores no Ensino Fundamental e Médio na Diretoria de Ensino de Limeira (SP). A partir da aplicação de questionários nas escolas públicas, objetivando identificar as formas de desenvolvimento de conteúdos, os dados da pesquisa revelaram a existência de um ciclo de reprodução das dificuldades de aprendizagens a partir da seleção dos conteúdos realizadas pelos docentes. No texto refletimos sobre as representações dos professores no ensino de Geografia, a complexidade da realidade do ensino público no estado de São Paulo, no contexto de suas políticas públicas. Ao colocar a escola como espaço para adoção de práticas pedagógicas que homogeneízam o ensino, o Estado tem imposto parâmetros e índices a serem alcançados nas avaliações externas, prejudicando as diferentes aprendizagens, atendendo a objetivos e interesses determinados externamente ao seu contexto, desvinculados das realidades locais.
\end{abstract}

Palavras-chave: Geografia; Ensino; Representação; Formação docente.

\begin{abstract}
:
This paper presents a reflection about the contents prioritized in the development of the curriculum, with data that were collected through the application of a questionnaire to Geography teachers of School Board of Limeira (SP). The research results indicate that there is a reproduction cycle of learning difficulties from the selection of the contents by the teachers. In the text there is a consideration about the instructor representation to the Geography teaching, the complexity of public education reality in the state of São Paulo in the context of the public policy putting the school as a space to the adaption of pedagogical practices that homogenize the teaching, the State has impored parameters and indexes to be reached in the external avaliations, impairing the different learning ways, complying with the aims and concerns externaly determined to its context, unrelated to local realities.
\end{abstract}

Key-words: Geography; Teaching; Representation; Teaching training.

\section{Introdução}

O presente trabalho visa apresentar uma reflexão sobre os conteúdos do currículo de Geografia desenvolvidos pelos professores no ensino Fundamental e Médio, tendo em vista as representações sociais dos docentes, acerca daqueles em que os alunos apresentam maiores dificuldades/ facilidades no processo de aprendizagem. As reflexões sobre o Currículo de Geografia que são desenvolvidas no 
Brasil apontam para questões importantes tais como: definição e seleção de conteúdos, formação docente e representações sociais, cultura escolar e conhecimento científico, materiais e métodos de ensino, prática docente, políticas públicas e educação formal que são em geral, temas centrais que objetivam contribuir e transformar a realidade escolar brasileira. Constatam estas análises que a forma como o Currículo é estruturado em manuais ou documentos oficiais por si só, não garante a eficiência na aprendizagem dos alunos, nem tão pouco, uma transformação radical e imediata nas relações que se estabelecem entre professores e alunos no processo de ensino e aprendizagem.

Durante a pesquisa de Doutorado desenvolvida junto ao Programa de Pós-graduação em Geografia da Unesp Rio Claro (2010 - 2015), ao investigar os possíveis impactos da implantação do currículo oficial da SEE/SP, no desempenho dos candidatos das escolas públicas na prova de conhecimentos gerais do vestibular da VUNESP (2008 a 2010), coletamos informações sobre a seleção dos conteúdos pelos professores de Geografia da Diretoria de Ensino de Limeira (SP).

Neste trabalho buscamos abordar a prática docente em sala de aula tendo como foco investigativo os saberes expressos essencialmente a partir das representações dos professores de Geografia, a respeito da seleção dos conteúdos e dos fatores que influenciam os processos de ensino e aprendizagem em sala de aula.

Ao estudar a geografia escolar, Gonçalves (2006) estabelece uma leitura sobre as formas de construção social do currículo evidenciando, a partir de diferentes autores, como os sistemas educativos fazem da escola um lugar privilegiado para difusão dos processos de racionalização e sistematização do controle social, a fim da manutenção de metas e padrões hegemonicamente prédefinidos. Constitui assim o currículo como um campo de luta entre forças que ao mesmo tempo são disseminadoras da ideologia dominante e trazem em si possibilidades de mudanças sociais.

Reforçando esta ideia com um caráter mais crítico, Oliva (2009) indicou a distância entre a produção da academia e o ensino médio, no caso da Geografia. Para o autor esta relação deve ser analisada sob dois cenários: o do mundo acadêmico e o mundo do ensino médio em busca de uma caracterização mínima esclarecedora a respeito dos aspectos que dificultam a renovação da geografia e, portanto, outras perspectivas de desenvolvimento dos currículos.

No mundo acadêmico destacou que um conjunto imenso de instituições privadas de ensino superior em que predominam os cursos de licenciatura em Geografia, na maioria dos casos, haveria uma geografia tradicional, alheia aos movimentos de renovação e sem um canal de comunicação com os grupos de renovadores "enclausurados" nas universidades majoritariamente públicas. (OLIVA. 2009, p. 38).

Já no cenário do ensino médio, o sistema público estadual estaria com grandes dificuldades para que os professores pudessem buscar o aperfeiçoamento e a renovação de modo constante e também, não seria menos preocupante, a situação do ensino nas instituições privadas com o fortalecimento de metodologias pedagógicas burocratizadas que deixariam para último plano as reflexões sobre um currículo em movimento.

Neste artigo não foram estabelecidas relações diretas entre prática docente, currículo e desempenho dos alunos nos sistemas de avaliação externa, mas a aproximação entre estes elementos constituintes da realidade educacional foi a metodologia utilizada para o diálogo entre o currículo oficial da SEE/SP e as representações dos docentes sobre a seleção dos conteúdos em Geografia.

Ao investigar os conteúdos selecionados pelos professores em suas práticas consideramos que a escola e a sala de aula são espaços em que se concretizam as definições sobre a política e o planejamento que as sociedades estabelecem sobre si próprias. Para Azevedo (2004) o cotidiano escolar representa o elo final de uma complexa cadeia que se monta para dar concretude a uma política pública e, por isso, deve sempre estar à frente em uma investigação a respeito do currículo.

Em 2008, a Secretaria Estadual da Educação iniciou um conjunto de ações que visavam imprimir uma lógica e dinâmica organizacional nas escolas, impostas sob o discurso da melhoria da qualidade do ensino da rede estadual pública. Entre as ações, a SEE/SP publicou documento que passaram a orientar o trabalho nas escolas estaduais, como a Proposta Curricular (São Paulo, 2008), organizada 
por área de conhecimento e também por componente curricular do Ensino Fundamental (Ciclo II) e Ensino Médio.

Os documentos de divulgação do currículo foram acompanhados por materiais pedagógicos específicos para cada disciplina denominados "Cadernos do Professor" e "Cadernos do Aluno", organizados por disciplinas, distribuídos bimestralmente aos alunos de $6^{\circ}$ ao 9 o ano do ensino fundamental e $1^{\mathrm{o}}$ ao $3^{\mathrm{o}}$ ano do ensino médio.

O programa no Currículo Oficial está organizado a partir de conteúdos básicos que devem objetivar a compreensão das relações que se estabelecem entre os objetos naturais e os construídos pela atividade humana priorizando o estudo do território, da paisagem e do lugar.

O objeto central do ensino da Geografia reside, portanto, no estudo do espaço geográfico, abrangendo o conjunto de relações que se estabelece entre os objetos naturais e os construídos pela atividade humana, ou seja, os artefatos sociais. Neste sentido, enquanto o "tempo da natureza" é regulado por processos bioquímicos e físicos, responsáveis pela produção e interação dos objetos naturais, o "tempo histórico" responsabiliza-se por perpetuar as marcas acumuladas pela atividade humana como produtora de artefatos sociais (Currículo Oficial do Estado de São Paulo, p. 77) ${ }^{1}$.

Na prática, pretende-se que ocorra um processo de alfabetização geográfica que segundo Sayão e Nunes (2011) se dá por meio de dois elementos centrais: os conceitos e as habilidades. A alfabetização pressupõe ações e capacidades inerentes ao próprio processo de ensino-aprendizagem, que devem ser desenvolvidas em um processo de aquisição da linguagem específica. Ocorre que muitas vezes o ensino de Geografia ainda é fragmentado e a prática dos professores pautada em recursos pouco diversificados e voltados para a memorização das informações (SOUZA, KATUTA, 2001).

Além disso, os "Cadernos" da SEE/SP imposta e apresentados como "inovação metodológica" exigiram o entendimento de "nova metodologia" de trabalho e geraram grandes incertezas nas práticas docentes, em muitos casos passaram a ser utilizados como instrumentos de controle sobre os conteúdos a serem abordados pelos professores.

Sob o discurso da padronização dos conteúdos, de que os alunos deveriam ter condições iguais para realizarem as avaliações de sistema, especialmente o SARESP, os Cadernos limitaram a liberdade dos professores na organização dos conteúdos e no ritmo de suas práticas pedagógicas, considerando o desenvolvimento dos alunos, bem como dos projetos pedagógicos que já pertenciam à cultura das unidades escolares.

Esta prática nas políticas públicas assemelha-se ao desmonte simbólico da escola pelas avaliações de sistema que transformam as escolas em negócios (de competências e habilidades), que devem apresentar resultados que satisfaçam os políticos, que prometem milagres econômicos e sociais com uma "educação de qualidade" comprovada pelos testes padronizados (VASCONCELLOS,2011; MARTINS, 2011).

As avaliações, transformadas em índices, passaram então a compor o quadro estrutural para o planejamento das ações da SEE/SP, e trouxeram impactos sobre as formas de organização do trabalho docente nas escolas, ainda pouco investigadas pelas pesquisas acadêmicas.

\footnotetext{
${ }^{1}$ Evidentemente que não é objetivo deste trabalho analisar toda a concepção de geografia que se realiza nesta proposta, mas evidencia-se que a determinação de análise sobre os "objetos naturais e sociais", secundariza as relações humanas e parte de uma concepção de que as relações são entre objetos e espacialidade e não entre sujeitos com intencionalidade e tensões de classe. Trata-se de uma infirmação dos sujeitos concretos (MOREIRA, 1982) e uma afirmação de que a Geografia não é uma ciência dos homens mas dos espaços. Segundo Sierra o geógrafo francês Vidal de La Blache tem uma frase síntese desse conjunto de leituras e representações geográficas: "La geografía es la ciencia de los lugares, no ciencia de los hombres (SIERRA, 1989:5).
} 


\section{Desenvolvimento}

A Diretoria de Limeira (DERLIM) foi instituída em 1999, ficando sob sua jurisdição além de Limeira, oito municípios do interior do estado de São Paulo: Arthur Nogueira, Cordeirópolis, Cosmópolis, Engenheiro Coelho, Ipeúna, Iracemápolis, Rio Claro e Santa Gertrudes. A DERLIM orienta todas as escolas dos municípios de sua área de abrangência (públicas e privadas), sendo responsável direta por 68 unidades que oferecem ensino fundamental, médio e educação de jovens e adultos (EJA).

A base empírica da pesquisa se estruturou a partir da aplicação de questionários nas escolas, tendo como foco dois temas centrais: os conteúdos priorizados pelos professores no desenvolvimento do currículo e os conteúdos nos quais os alunos apresentam maiores dificuldades/ facilidades no desenvolvimento da aprendizagem. Complementarmente foram coletados dados sobre o grau de facilidade dos professores no desenvolvimento de suas práticas docentes ao abordarem determinados conteúdos da Geografia.

0 referencial teórico utilizado para análise foi o conceito de Representação Social definido por Moscovici (2003), por compreendermos que os saberes docentes são construídos ao longo da prática, como resultado de um conjunto de ideias socialmente partilhadas a respeito do que representam o currículo e a seleção dos conteúdos. Embora captada de forma individual, através dos questionários, as opiniões dos professores manifestam representações sociais e foram definidas por Moscovici como:

Um sistema de valores, ideias e práticas, com uma dupla função: primeiro, estabelecer uma ordem que possibilitará às pessoas orientar-se em seu mundo material e social e controlá-lo; e, em segundo lugar, possibilitar que a comunicação seja possível entre os membros de uma comunidade, fornecendo-lhes um código para nomear e classificar, sem ambiguidade, os vários aspectos de seu mundo e da sua história individual e social (MOSCOVICI, 2003, p. 21).

Assim compreende-se que definição de conteúdos e seu desenvolvimento, implicam em representações sociais dos docentes acerca da centralidade do conhecimento em geografia e que media sua prática social e, por sua vez, a estrutura formativa/formadora. Para a investigação sobre os conteúdos, a estratégia incluiu a divisão do instrumento de coleta em quatro partes, onde foi apresentado um rol de conteúdos ${ }^{2}$ previamente selecionados, a partir dos quais os professores deveriam indicar:

1. o grau de importância dos conteúdos de suas aulas na formação dos alunos, sendo (1) pouco importante e (5) muito importante;

2. a relação grau de importância /carga horária utilizada com os conteúdos ao longo da carga horária letiva anual, sendo (1) pouco importante, pouco tempo e (5) muito importante, muito tempo;

3. o nível de dificuldade dos alunos na aprendizagem dos conteúdos, sendo (1) muita dificuldade e (5) pouca dificuldade;

4. o grau da facilidade ao trabalhar os conteúdos com os alunos, sendo (1) muito fácil; (2) fácil; (3) intermediário; (4) difícil e (5) muito difícil.

A análise dos dados permitiu a elaboração de um quadro síntese para a reflexão sobre a definição dos conteúdos abordados pelos professores em suas práticas.

\footnotetext{
2 Para a apresentação dos conteúdos nos questionários tomamos como base a grade de Geografia da Proposta Curricular da SEE/SP páginas 47 à 53 (2008), organizando-os em 17 itens que contemplavam os temas para o Ensino Fundamental (CicloII) e Ensino Médio.
} 
Quadro 1 - Referencial dos conteúdos na prática docente dos professores de Geografia da DERLIM

\begin{tabular}{|l|l|}
\hline \multirow{2}{*}{ Conteúdos considerados muito importantes } & $\begin{array}{l}\text { Educação Ambiental, Cartografia } \\
\text { Redes Mundiais e Geopolítica } \\
\text { Globalização }\end{array}$ \\
\hline \multirow{3}{*}{ Maior carga horária anual } & $\begin{array}{l}\text { Globalização e Questões ambientais } \\
\text { Educação ambiental } \\
\text { Redes Mundiais }\end{array}$ \\
\hline \multirow{3}{*}{ Nível de dificuldade dos alunos } & Muita dificuldade \\
& Escala, Cartografia e Geopolítica \\
\cline { 2 - 3 } & $\begin{array}{l}\text { Pouca dificuldade } \\
\text { Questões ambientais, Vegetação e Redes } \\
\text { Mundiais }\end{array}$ \\
\hline \multirow{3}{*}{$\begin{array}{l}\text { Nível de facilidade dos professores naito fácil } \\
\text { abordagem dos conteúdos }\end{array}$} & $\begin{array}{l}\text { Questões ambientais, Globalização, Recursos } \\
\text { naturais e Gestão do território }\end{array}$ \\
\cline { 2 - 2 } & $\begin{array}{l}\text { Muito difícil } \\
\text { Escala e Cartografia }\end{array}$ \\
\hline
\end{tabular}

Fonte: pesquisa realizada pela autora com professores de Geografia de educação básica, 1o semestre de 2013.

Constatamos que a educação ambiental foi considerada a temática mais importante na definição dos conteúdos e pode estar relacionado ao fato dos professores perceberem na Geografia, a potencialidade para tratar sobre esta temática de caráter transdisciplinar.

Compreendendo a importância das questões sobre seleção dos conteúdos (ZABALA, 2002) ${ }^{3}$ a sequência dos questionários apresentou aos professores a possibilidade de indicarem três conteúdos que consideraram de grande importância, com o seguinte resultado: cartografia, redes mundiais e geopolíticas (com as mesmas proporções) e globalização. Estes conteúdos também foram citados como os que ocupam a maior carga horária das aulas ao longo do ano.

Da relação entre importância dos conteúdos/ carga horária/ dificuldade dos alunos/facilidade na prática docente concluímos que os professores em geral, dedicam maior tempo de suas aulas com os conteúdos que consideram importantes para a formação dos alunos. Estabeleceu-se então a clara relação entre o grau de importância dado a determinados conteúdos e o tempo destinado ao trabalho docente sobre estes mesmos conteúdos ${ }^{4}$.

Por outro lado, os conteúdos indicados como de "fácil aprendizagem" pelos alunos e também para a abordagem nas práticas didáticas dos professores nos permitiu levantar a seguinte reflexão: será que a maior facilidade dos alunos não estaria relacionada ao fato de que os professores consideram estes temas mais fáceis de serem abordados em sala de aula e, portanto, acabam ocupando maior tempo nas aulas ao longo de um período letivo?

Sobre as dificuldades dos alunos identificamos que os conteúdos "escala, cartografia e geopolítica" foram os mais indicados como de difícil aprendizagem dos alunos, sendo escala e cartografia os conteúdos nos quais os professores apresentam maiores dificuldades para a abordagem em sua

\footnotetext{
3 Outro aspecto da seleção dos conteúdos deve ser destacado no que se refere ao resultado da função social do ensino. Por trás da seleção e da importância que se atribui a cada uma das disciplinas, existe uma clara determinação da função social do ensino. 0 por quê de algumas matérias e não de outras? Qual o papel de cada uma delas no currículo? São perguntas que devem levar principal questão: qual a função do sistema de ensino? Que tipo de cidadãos o ensino deve promover? 0 que ensinar? Os conteúdos de aprendizagem selecionados tornam concretas as respostas que definem a função social de cada sistema e que cada pessoa atribui ao ensino. (ZABALA, 2002, p. 19).

4 No Gráfico 1 apresentamos as representações dos professores sobre os fatores que dificultam a aprendizagem dos alunos. Foram considerados os resultados para os municípios de Limeira, Rio Claro e Outros municípios que representam respectivamente: $42 \%, 30 \%$ e $28 \%$ do total de escolas públicas estaduais da DERLIM, totalizando 68 unidades.
} 
prática docente.

Esta constatação apresenta semelhanças com a pesquisa realizada por Lock e Fuckner (2003) com professores de Geografia da região metropolitana de Florianópolis (SC). Nesta pesquisa, os autores constataram que a maioria dos professores formada em Geografia mencionou não saber como os mapas são feitos e que tinham dúvidas sobre alguns conteúdos específicos da cartografia. 0 mais relevante foi a projeção cartográfica que configurou como a dúvida mais problemática para $51 \%$ dos professores entrevistados, seguido de escala e coordenadas geográficas.

Almeida (1991) ao tratar dos estudos geográficos apontou a importância da seleção dos conteúdos tendo como partida os saberes dos alunos, mas que de nenhuma maneira este deveria permanecer como ponto de chegada. Destacou que na relação entre método e conteúdos a Geografia ensinada ao apresentar a relação do homem com o meio não poderia deixar de explicitar que a sociedade produz uma forma observável do espaço fruto das relações de trabalho nesta sociedade.

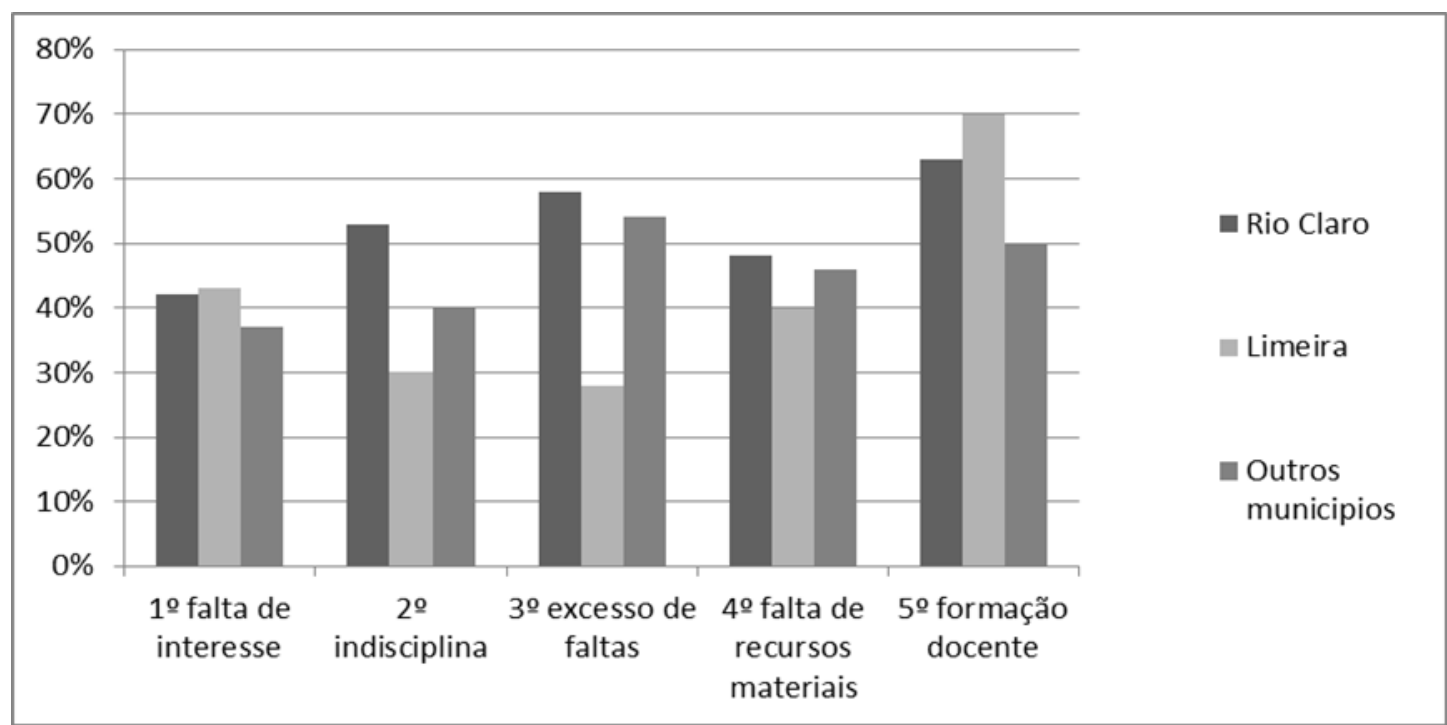

Gráfico 1 - Representações dos professores de Geografia sobre os fatores que dificultam a aprendizagem dos alunos - DERLIM, 2013.

Fonte: Pesquisa realizada e organizada pelos autores, $1^{\underline{0}}$ semestre 2013.

A importância atribuída aos conteúdos e a dificuldade formativa do professor pode ser percebida como uma contradição das respostas. No primeiro caso, polarizando importância com muito difícil, ou seja, há um reconhecimento, no caso da Cartografia especificamente, mas uma grande dificuldade de abordagem e sua não priorização. 0 mesmo ocorreu na dificuldade dos alunos com relação à Geopolítica e a importância do conceito de globalização, que simultaneamente é a facilidade do Professor. 0 que dizem estes conteúdos na questão formativa do mundo contemporâneo?

As facilidades dos alunos nas discussões ambientais, Vegetação e Redes, muitas vezes reforçam conceitos de mass media, decorativos e de contínua informação dos meios de comunicação. Refletimos sobre o quanto destas abordagens não passam assim, a serem conhecimentos tácitos e não de abstrações mais complexas dos estudantes.

\section{Considerações Finais}

Embora nossa análise não tenha contemplado outros elementos essenciais da aprendizagem dos alunos, tais como, as estratégias didáticas, recursos utilizados, projeto político pedagógico e o cotidiano escolar, consideramos que revelou-nos as representações que a maioria dos professores de 
Geografia possuem com relação à seleção dos conteúdos e ao grau de dificuldade enfrentado pelos alunos no processo de aprendizagem.

Os resultados desta pesquisa indicaram que as dificuldades dos alunos também são dificuldades dos professores e assim caracterizamos um ciclo de reprodução das dificuldades de aprendizagem. Dificuldades dos professores que geralmente estão associadas a questões de formação, mas que também dizem respeito à adoção de práticas pedagógicas que homogeneízam o ensino e prejudicam as diferentes aprendizagens.

As representações dos professores também indicaram que os alunos apresentam maior facilidade nos conteúdos considerados como mais fáceis de serem abordados em suas práticas docentes. Ficou evidente que a formação docente apareceu como último fator a ser considerado pelos professores na dificuldade de aprendizagem dos alunos, entretanto, nas perguntas abertas do questionário indicaram a necessidade de cursos de formação que estivessem relacionados à realidade da sala de aula, onde pudessem trocar experiências para melhorar a prática docente.

Para a maioria dos professores existe uma representação de que a falta de interesse dos alunos é o principal fator para a dificuldade de aprendizagem, constatação que reforça a necessidade de reflexão no contexto do ensino publico no estado de São Paulo. Refletir sobre as representações docentes para o ensino de Geografia, exigi-nos compreender que a escola tem sido espaço para adoção de práticas pedagógicas que homogeneízam o ensino e de políticas que impõem parâmetros e índices a serem alcançados nas avaliações externas, prejudicando as diferentes aprendizagens para atender a objetivos e interesses determinados externamente ao seu contexto, desvinculados das realidades locais.

Neste sentido, é necessário que possamos ampliar a discussão para refletirmos sobre a "atual forma escola" como bem coloca-nos FREITAS (2010) ao afirmar que, existe uma artificialidade intencional nas salas de aula tornando-a sem significado para os estudantes, mas de grande serventia à reprodução das relações sociais.

Ao adotar as representações docentes para a seleção dos conteúdos evidenciamos o processo de reprodução das dificuldades em suas práticas pedagógicas que analisadas isoladamente correm o risco de reproduzir o efeito de distorção do fenômeno frente à complexidade da escola pública. No entanto, as evidências desta pesquisa têm alicerçado outros projetos de investigação para que possamos contribuir efetivamente na concretização do currículo de Geografia no estado de São Paulo.

\section{Referências}

ALMEIDA, R. D. de. A propósito da questão teórico metodológica sobre o ensino de Geografia. In Revista Terra Livre. São Paulo: AGB/Marco Zero (8): 83-90, 1991.

AZEVEDO, J. M. Lins de. A educação como política pública. Campinas-SP: Autores Associados, 2004.

CARLOS, A.F. de A (org.); A geografia na sala de aula. São Paulo, Contexto, 1999.

CURY, I.L.R. $O$ vestibular da unesp: sobre acesso à educação superior e o currículo de geografia na educação básica (2006-2012). 1aㅡ ed. São Paulo: Cultura Acadêmica, 2016.

FREITAS, L.C. Avaliação: para além da "forma escola". Revista Educação: Teoria e prática - v. 20, n.35, jul-dez. 2010, p. 89-99.

GONÇALVES, A.R. Os espaços-tempos cotidianos na geografia escolar: do currículo oficial e do currículo praticado. Tese (doutorado) - Universidade Estadual Paulista, Instituto de Geociências e Ciências Exatas, Rio Claro : [s.n.], 2006, $204 \mathrm{f}$.

LOCH, R. E. N. e FUCKNER, M.A Do ensino de cartografia na universidade à cartografia que se ensina na educação básica. Anais do XXI Congresso de Brasileiro de Cartografia, Belo Horizonte, MG, 2003.10 p.

MADEIRA, M. Representações sociais e educação: importância teórico-metodológica de uma relação. 
In: MOREIRA, A. S. P. (Org.). Representações sociais: teoria e prática. João Pessoa: Editora Universitária, 2001. p. 123-146.

MARTINS, L. O desenvolvimento do psiquismo e a educação escolar: contribuições à luz da psicologia histórico-cultural e da pedagogia histórico-crítica. FAAC/UNESP: Bauru-SP, 2011 (Tese de Livre Docência).

MOREIRA, R. Geografia, Ecologia, Ideologia: a "totalidade homem-meio" hoje (espaço e processo do trabalho). Vozes, 1982.

MOSCOVICI, S. Representações sociais: investigações em psicologia social. Petrópolis:Vozes, 2003.

OLIVA, J T. Ensino de Geografia: um retrato desnecessário. In: Carlos, A. F (org). A Geografia na Sala de Aula. (8), 3ª̣ed. São Paulo, Contexto, 2009, p. 34-49.

São Paulo (Estado) Secretaria da Educação. Currículo do Estado de São Paulo: Ciências Humanas e suas tecnologias / Secretaria da Educação; coordenação geral, Maria Inês Fini; coordenação de área, Paulo Miceli. - São Paulo : SEE, 2010.

SAYÃO, L. G. dos S; NUNES F.G. A geografia no Exame Nacional do Ensino Médio (ENEM): uma análise a partir das provas do período 2005 - 2008. Revista Ensino de Geografia Uberlândia, v. 2, n. 3, p. 36-59, jul./dez. 2011.

Secretaria Estadual da Educação do Estado de São Paulo. Proposta Curricular do Estado de São Paulo Geografia. Coord. Maria Inês Fini. - São Paulo: SEE, 2008.

SIERRA, C. La Nueva Historia: geografía histórica www.anep.edu.uy/uruguayglobal/fotos/option_media_188.pdf. Capturado em 15/12/2010

SOUZA, J. G.; KATUTA, Â. M.; Geografia e conhecimentos cartográficos: a cartografia no movimento de renovação da geografia brasileira e a importância do uso de mapas. São Paulo: Editora UNESP, 2001.

VASCONCELlOS, C. dos S. Currículo: A Atividade Humana como Princípio Educativo, 3ạ ed. São Paulo: Liberdade, 2011.

ZABALA, A. Enfoque globalizador e pensamento complexo: uma proposta para o currículo escolar. Trad. Ernani Rosa. Porto Alegre: Artmed, 2002. 